\title{
Reciprocal effects of health and economic well-being among older adults in Taiwan and Beijing
}

Kristine R. Baker

Mary Beth Ofstedal

Zachary Zimmer

Population Council

Zhe Tang

Yi-Li Chuang

Follow this and additional works at: https://knowledgecommons.popcouncil.org/departments_sbsr-pgy

Part of the Demography, Population, and Ecology Commons, Family, Life Course, and Society Commons, Gerontology Commons, and the International Public Health Commons How does access to this work benefit you? Let us know!

\section{Recommended Citation}

Baker, Kristine R., Mary Beth Ofstedal, Zachary Zimmer, Zhe Tang, and Yi-Li Chuang. 2005. "Reciprocal effects of health and economic well-being among older adults in Taiwan and Beijing," Policy Research Division Working Paper no. 197. New York: Population Council. 


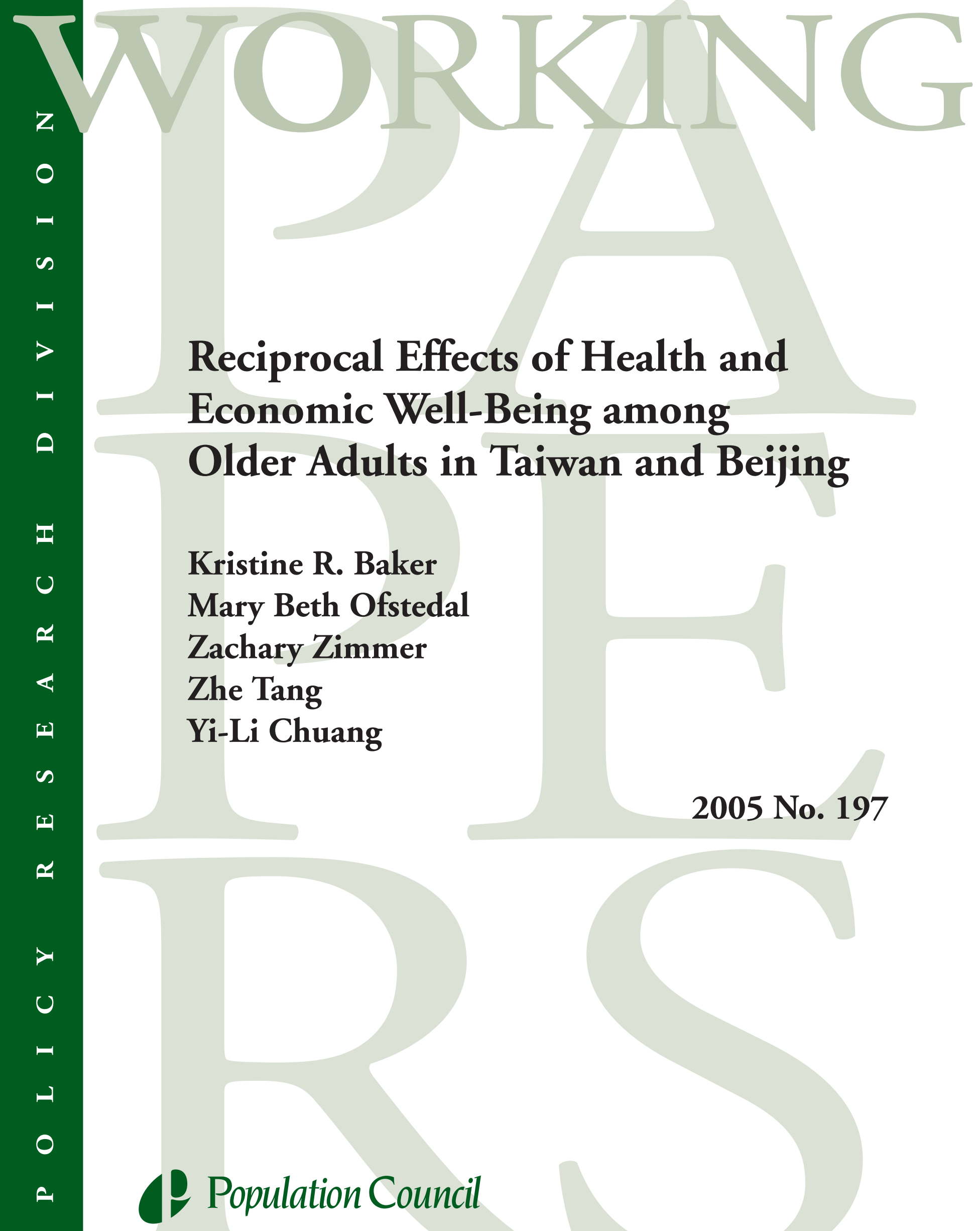




\section{(P) Population Council}

One Dag Hammarskjold Plaza

New York, New York 10017 USA

www.popcouncil.org

pubinfo@popcouncil.org

This material may not be reproduced without written permission from the authors. For a list of Policy Research Division Working Papers, including those that are currently available for downloading in PDF format, see www.popcouncil.org/publications/wp/prd/rdwplist.html.

ISSN: $1554-8538$

(C) 2005 The Population Council, Inc. 


\title{
Reciprocal Effects of Health and Economic Well-Being among Older Adults in Taiwan and Beijing
}

\author{
Kristine R. Baker, Mary Beth Ofstedal, Zachary Zimmer, \\ Zhe Tang, and Yi-Li Chuang
}

Kristine R. Baker is Postdoctoral Fellow, Population Studies Center, University of Michigan. Mary Beth Ofstedal is Associate Research Scientist, Survey Research Center and Population Studies Center, Institute for Social Research, University of Michigan. Zachary Zimmer is Associate, Population Council. Zhe Tang is Head and Director of Research, Capital University of Medical Science, Xuanwu Hospital, Beijing. Yi-Li Chuang is Section Chief, Bureau of Health Promotion, Department of Health, Taiwan.

Acknowledgments: Research for this paper is supported by parallel grants from the National Institute on Aging: R01 AG20063-01 and R01 AG20072-01, and the Training in the Demography and Economics of Aging grant: 5 T32 AG00221.

An earlier version of this paper was presented at the Gerontological Society of America meetings in Washington D.C., November 21, 2004. 


\begin{abstract}
The objectives of this study are threefold: 1) to examine whether socioeconomic status disparities in health are found in non-Western settings; 2) to assess whether socioeconomic status gradients in health endure into older ages; and 3) to evaluate the direction of causality between health and socioeconomic status. Using data from multiple waves of two longitudinal panel studies of older adults: the Survey of Health and Living Status of the Elderly in Taiwan (1993, 1996, 1999) and the Beijing Multidimensional Longitudinal Study of Aging (1992, 1994, 1997), the paper employs structural equation models to test hypotheses concerning cross-lagged and reciprocal influences between economic well-being and health. Findings provide evidence for reciprocal effects of economic well-being and health among older adults in both Taiwan and Beijing. Those with higher levels of economic well-being have lower levels of functional limitation over time, and those with higher levels of functional limitation have lower levels of economic well-being over time. Consistent with studies based in the United States and Europe, findings from Asia indicate economic differentials in functional health among older adults, highlighting the wider applicability of these associations across settings with very different systems of health care and stratification. Results underscore the importance of considering reciprocal influences in studies of socioeconomic status and health.
\end{abstract}


A wealth of evidence, some from as far back as the nineteenth century, links higher levels of socioeconomic status to more favorable health outcomes (Antonovsky, 1967). The modern discourse on the topic has been facilitated by large-scale and influential studies conducted in the United States and England that showed both mortality and chronic illness gradations across levels of education, income, and, particularly in studies in the United Kingdom, occupation (Conover, 1973; Kitagawa and Hauser, 1973; Marmot, Shipley, and Rose, 1984; Townsend and Davidson, 1982). Since the early 1990s, studies in a number of developed countries have confirmed a health advantage for persons with higher levels of socioeconomic status, considering a variety of health outcomes, including mortality, morbidity, and specific chronic diseases (Backlund, Sorlie, and Johnson, 1996; Elo and Preston, 1995; Gregorio, Walsh, and Paturzo, 1997; Hemingway, Nicholson, and Marmot, 1997; Kawachi et al., 1997; Kirchgassler, 1998; Lagasse et al., 1990; Lantz et al., 1998; Mackenbach et al., 1997; Spruit, 1990; Sundquist and Johansson, 1997; Wolfson et al., 1993). Several other studies examining trend data have suggested that gaps in social inequalities in health are widening (Feldman et al., 1989; Pamuk, 1985; Pappas et al., 1993; Queen et al., 1994).

Despite this history of research and persistent and robust results linking socioeconomic status and health, several unanswered questions remain. First is the issue of whether health inequalities endure into old age. Some analysts have observed a convergence in rates of mortality and other health outcomes at older ages (Elo and Preston, 1995; House et al., 1990; Hurd, McFadden, and Merrill, 1999). One reason for a possible narrowing of a socioeconomic gradient with age is a selection effect whereby higher mortality and attrition rates among persons of lower status across all ages leave behind a more select and robust group surviving to older ages (Beckett, 2000; Markides and Machalek, 1984; Robert and House, 1994). Still, while there is some evidence for convergence in mortality, inequalities in health into older ages appear to be sustained when health is measured as physical functioning outcomes, such as activities and instrumental activities of daily living (Guralnik et al., 1993; Kaplan et al., 1993; Knesebeck et al., 2003), and particularly when examining the incidence or onset of functional disorder (Grundy and Glaser, 2000; Melzer et al., 2001). These differences may reflect a cumulative impact of socioeconomic status on health (Ross and Wu, 1996; Victor, 1991).

Second, given the limited number of studies in non-Western settings, the relationship between socioeconomic status and functional outcomes among older adults outside the West remains unclear. It is reasonable to project similar associations across other diverse settings, particularly if socioeconomic indicators include proximate factors that might influence health outcomes, such as environmental risks and ability to purchase health care (Link and Phelan, 1995; National Research Council, 2001). Liang, Liu, and Gu (2001) and Yu and Wang (1993) have demonstrated socioeconomic gradients in functional status among older adults in China. Zimmer et al. (1998) found similar effects in Taiwan. Alternatively, Zimmer et al. (2004) showed varying influences of socioeconomic status on physical functioning outcomes of older adults in Taiwan, the Philippines, and Thailand, with associations being strong in Taiwan, weak in Thailand, and nearly nonexistent in the Philippines. In China, Zimmer and Kwong (2004) found varying results across different 
measures of socioeconomic status, while $\mathrm{Gu}$ and $\mathrm{Yi}$ (2004) showed weak effects of education on onset of and recovery from disability among persons 80 years of age and older. Thus, the little that has been written about the association in non-Western settings is contradictory.

Third, although recent studies have attempted to sort out the causal direction of the association, disagreement continues over this point. While it has been conventional in most disciplines to assume that lower socioeconomic status is responsible for poor health in Western societies (Carr-Hill, 1987; Wilkinson, 1986; Williams, 1990), some economists have argued that at older ages the causality may run primarily from health to socioeconomic status, through factors such as the ability to work and thereby accumulate wealth (Smith, 1999). A recent argument holds that the convergence in gradations in mortality at very old ages suggests that socioeconomic status and health are influenced by unobservable individual characteristics that are responsible for both (Hurd, McFadden, and Merrill, 1999). The direction may also depend upon the particular measure of socioeconomic status under scrutiny. Education, for instance, is generally considered to remain constant throughout adulthood for most individuals (Ross and Wu, 1995; Winkleby et al., 1992). Income, however, is far more likely to change during later life, and this change may in part be a consequence of changes in health. For example, worsening health may cause older individuals to withdraw from the labor market.

The current study examines the dynamic association between economic well-being and health in two Asian settings: Taiwan and Beijing. Drawing on data from three waves of ongoing panel surveys of older adults in both settings, the study examines whether the association between socioeconomic status and functional health that has been observed for older adults in the West is also observed in a less developed and culturally distinct part of the world. In addition, the availability of multiple waves of panel data allows us to assess the causal direction of the relationship. We do this by employing a latent variable structural equation modeling approach to test hypotheses concerning reciprocal influences between socioeconomic status and health (Kessler and Greenberg, 1981). Considering functional health as a latent construct permits a conceptual integration of indicators that are available in surveys and allows us to examine how these indicators and latent constructs are related.

The model that we test is presented in Figure 1. The model hypothesizes that both functional limitation and economic well-being at one wave influence functional limitation and economic well-being at a follow-up wave, controlling for compositional variables such as age and sex. Therefore, we hypothesize that there are cross-lagged reciprocal effects and that both causal connections (economic well-being on functional limitation and functional limitation on economic well-being) exist. We make no a priori assumptions regarding which of the associations is stronger. We expect associations between functional limitation and economic well-being to be negative; that is, higher levels of functional limitation at one wave will be associated with lower economic well-being in the next, and higher economic well-being at one wave will be associated with lower levels of functional limitation in the next. In contrast, functional limitation and economic well-being across waves are expected to be positively related over time; that is, higher functional limitation and economic wellbeing at one wave are expected to be associated with higher limitation and economic well- 
being in the next. The figure also hypothesizes that functional limitation is a latent construct comprised of three components: activities of daily living (ADL), instrumental activities of daily living, (IADL) and Nagi physical functioning tasks (Nagi). Finally, we hypothesize that effects will be found in both Taiwan and Beijing, although we make no assumption regarding differences in the magnitude of the associations across settings.

\section{The STUdy SeTtings}

As a consequence of unprecedented reductions in fertility and substantial improvements in old-age mortality, the population aging taking place throughout East Asia is among the fastest in the world (Hermalin and Myers, 2002). In 1995 an estimated 147 million persons were aged 60 and older in East Asia. This represents a doubling since 1975 , and these numbers are expected to further increase nearly threefold by 2030 (United Nations, 2001). The fraction of persons aged 60 and older has increased at an annual rate of about 3 percent between 1975 and 1995 and is expected to continue at a slightly higher rate through 2030. This rate of growth far exceeds the rates experienced in the United States or Europe (Hermalin and Myers, 2002). Future growth will be fastest for the oldest old (aged 80 and older), for whom the prevalence of health problems is highest. In East Asia, the oldest old population is expected to more than double between 1999 and 2050 as a percent of both the total population and the elderly population (United Nations, 2001).

Within East Asia, Beijing and Taiwan make for an informative comparative study. The population of Taiwan is about 22 million, while Beijing contains about 13 million residents. The two societies share a similar Chinese culture, characterized by filial piety and high rates of coresidence between older adults and their adult children (Fang, 1990; Hermalin, Ofstedal, and Chang, 1996; Lee, Parish, and Willis, 1994; Whyte, 2003). The majority of both populations resides in urban areas, but a substantial number also live in rural areas. Both settings have been undergoing rapid aging of their populations due to swiftly declining fertility, and both have experienced rapid economic growth. These changes have policymakers in both societies concerned because of the potential implications for future disease burdens and associated demands for informal and formal care. Although it has been standard in both Taiwan and Beijing to expect adult children to care for parents, both on an instrumental and economic basis, declining family sizes brought about by rapid drops in fertility, and changes in parent-child roles instigated by modernization of the economy, have prompted policymakers to question whether greater responsibility for care and support of the older population will be placed on the public at large.

There are also obvious differences between the two societies. Mainland China's fertility decline is often attributed to government policies that penalize couples who have more than one or two children, while Taiwan's is thought to be more individually motivated (Jiang and Zhang, 2000; Poston, 1992). Taiwan's economy has been developing steadily for several decades, while Beijing's has undergone rapid growth just over the last several years. The settings are also distinguished by obvious differences with respect to the nature of social stratification and political histories (Ebrey, 2000; Roy, 2003). 
It is difficult to predict how these similarities and differences might affect the relationship between economic well-being and physical functioning. One might expect associations to be more apparent in Taiwan, where a more distinctive system of stratification is thought to exist and a market-based economy has been in place for a longer time, helping to segregate populations by class. Class distinctions may be less apparent in China, where a socialist economy has been in place for more than half a century. Conversely, the health infrastructure in Taiwan is more developed, and in 1995 Taiwan instituted a Universal Health Insurance program that has, theoretically, provided equal access to health care for older adults. This may mute the effects of economic well-being on health. Health care in China has improved dramatically in cities, but there is mounting evidence that good-quality care at affordable costs is becoming more difficult to obtain in rural areas, where individuals tend to have much lower socioeconomic standing than their urban counterparts (Beach, 2001; Shi, 1993). A gap in the socioeconomic gradient with respect to health care may increase differences in health outcomes.

\section{DATA AND MEASURES \\ Data}

Our data for Taiwan come from the Survey of Health and Living Status of the Elderly in Taiwan (Hermalin, Liang, and Chang, 1989), a nationally representative panel survey of older adults. The original survey took place in 1989 and comprised 4,049 persons aged 60 years and older. In-person follow-up interviews were conducted in 1993, 1996, and 1999, and abbreviated telephone interviews were conducted in 1991 and 1995. In 1996, the sample was refreshed and expanded to include a new cohort of individuals between ages 50 and 66. The analyses presented here are based on the original cohort that entered the study in 1989. To maximize consistency in measures across waves, the data come from 1993, 1996 and 1999 rounds. The response rate was 93 percent in the baseline wave, and ranged between 89 and 92 percent at each of the follow-up waves. The analysis sample includes 2,077 respondents who participated in the 1993, 1996, and 1999 surveys.

The Beijing data are from three waves of the Beijing Multidimensional Longitudinal

Study of Aging, conducted by the Capital University of Medical Science in Beijing. Wave 1 consisted of 3,257 adults aged 55 and older in 1992. Individuals in the sample were living in one of three administrative areas within Beijing municipality. The first, Xuan Wu, is a district located in metropolitan Beijing. The other two areas, Da Xing and Huai Ruo, are rural agricultural areas located up to 100 kilometers from the city. These three areas were chosen in order to represent the total municipal region with respect to socioeconomic and demographic characteristics, and the two agricultural areas were also chosen because of their rural environment. The response rate for the baseline wave was 90 percent. Interviews were conducted in person at the home of the respondent. The follow-ups were conducted in 1994 and 1997. Survival status was determined through interviews with those still living in the household and with others living nearby. Response rates for the follow-up waves were also about 90 percent. The analysis sample includes 2,001 respondents who participated in all three waves of the survey. More details on this study and the sampling 
procedures can be found in Department of Social Medicine (1995), Jiang et al. (2002), and Tang et al. (1999).

\section{Measures}

Table 1 shows wave 1 means and standard deviations for all individual measures used in the analysis for both Taiwan and Beijing. Information for other waves is available upon request. The measures are divided into three categories: items that make up functional limitation, items that make up the economic well-being index, and other covariates.

Functional limitation. Functional limitation is a latent variable with three components: activities of daily living (ADLs), instrumental activities of daily living (IADLs), and Nagi limitations. Each component relates to the ability to perform a set of functional tasks, although the types of tasks differ. ADLs refer to self-maintenance tasks, such as dressing and bathing (Katz et al., 1963). IADLs refer to tasks necessary for the maintenance of a living environment, such as shopping and taking care of finances (Lawton and Brody, 1969). Nagis refer to more general physical movements that individuals perform regularly, such as walking or climbing stairs (Nagi, 1965). For each component we derive a scale that combines items included in both surveys. There are five such ADL items, three IADL items, and two Nagis. In Taiwan, items were measured using a fourcategory response, ranging from no difficulty performing the task (coded 0 ) to being unable to do the task (coded 3). In Beijing, each item was measured using a three-category response, running from needing no assistance (coded 1) to being completely unable to do the task without assistance (coded 3). Scales are derived in two steps. First, the items that make up the scale are summed. For instance, summing the five ADL items in Taiwan results in a total score of between 0 and 15. Second, the sum is divided by the number of items not containing missing values. Thus, the ADL scale for Taiwan is a number ranging from 0 to 3 . These scaled scores are used in the structural equation model to represent the level of functional limitation. Because a higher score on each scale refers to a greater number and severity of functional problems, we refer to the latent variable as functional limitation.

Economic well-being. The Taiwan and Beijing surveys contain similar questions related to different aspects of economic well-being. Both surveys collect information on income, subjective economic well-being, and assets, although the specific assets that are asked about differ. To measure economic well-being for Taiwan and Beijing at each wave, we combine these items into a single scale using principal component factor analysis.

Assets are coded as 1 if owned or 0 if not owned. The assets used for Taiwan are land, savings, color television, air conditioner, and car. For Beijing they are a color television, electric fan, refrigerator, and washing machine. Two subjective measures of economic well-being, adequacy of income and satisfaction with income, are coded on scales ranging from 1 (worst off) to 5 (best off) in both settings. Income is measured as the respondent's and spouse's (if married) monthly income in New Taiwan Dollars (approximately 40 to 1 USD) and monthly Yuan (approximately 8 to 1 USD). 
A complication with using economic well-being (or any measure of socioeconomic status) in a structural equation model is that it is "induced" and as such should not be modeled as a latent variable (Bollen, 1989: 64-67). In other words, a change in one of the components of economic well-being, for example income, would induce a change in economic well-being, rather than the reverse. As noted above, we address this problem by using principal component factor analysis to construct an index of economic well-being for each wave of each survey (Dunteman, 1989; Filmer and Pritchett, 1999). The components load highly onto one factor for both Beijing and Taiwan at each wave, confirming that they represent a single construct. (The proportion of variance explained by the measures ranges from 47 to 50 percent across waves for Beijing and from 27 to 28 percent across waves for Taiwan.)

Covariates. Although our primary interest is the association between health and economic well-being, in the structural equation model we control for a number of factors that are thought to influence both of these outcomes. The controls include a mix of baseline and time-varying measures. The baseline controls include age $(60+$, in years), gender (female versus male), marital status (married versus not married), ethnicity (majority group versus minority group, with majority group being non-Mainlander in Taiwan and Han in Beijing), residence (urban versus rural), and education (no education, primary, junior high, senior high, and university or higher), scored 0 to 4 . The time-varying controls include living arrangements at each wave (alone or with spouse only versus living with children or others) and becoming widowed between waves (widowed between wave 1 and 2 versus not, widowed between waves 2 and 3 versus not).

\section{Missing data}

There are few missing data for the above measures, with the sole exception of income in Taiwan, for which information is missing for about 25 percent of respondents in waves 2 and 3. We imputed missing data values for income in Taiwan using Hotdeck Imputation (Rubin and Schenker, 1986), which selects imputed values randomly from a pool of complete cases. There is less than 3 percent missing data for other variables, and mean imputation was performed. T-tests show that people with missing data are similar to people with complete information, except that in Taiwan they are slightly less likely to be working in wave 3 and slightly more likely to be widowed in wave 1 .

\section{RESULTS}

\section{Measurement model for functional limitation}

To test the hypotheses indicated in Figure 1, we use structural equation modeling evaluated with AMOS 4 (Arbuckle and Wothke, 1999). The model consists of two parts estimated simultaneously: a measurement model specifying associations between observed and latent variables, and a structural model specifying the causal influences among latent and other variables.

The first step is a confirmatory factor analysis that tests the measurement model of functional limitation (Anderson and Gerbing, 1988; Kline, 1998). Table 2 presents fit results for three forms of measurement models. The first, the null model, assumes no 
covariance among the three components (ADL, IADL, and Nagi) and is used as a comparison. The second, a measurement model with independent errors, assumes covariance but does not allow for correlated errors of components across waves. The third allows errors to be correlated across waves; for instance, errors for the ADL score in wave 1 are allowed to correlate with errors for the ADL score in wave 2.

Several indexes are used to assess goodness-of-fit of the model. A common index is the relative likelihood ratio, which is computed by taking the model chi-square divided by degrees of freedom. However, given that this index is highly influenced by sample size, alternative measures that take sample size into account might be more appropriate. We therefore also use the comparative fit index (CFI) and the root mean square error of approximation (RMSEA).

An examination of the results for Model 2 in Table 2 shows that the assumption of independent errors is not supported; Model 2 does not yield adequate fit with respect to the indexes. Model 3, which allows for correlated errors, yields suitable results for both Taiwan and Beijing. Although not shown here, the factor loadings for the ADL, IADL, and Nagi scales in Model 3 are all in the expected direction and have significant t-values at the 0.001 level. These results are available upon request.

Structural model of functional limitation and socioeconomic status. Having identified a well-fitting measurement model, we next estimate the full structural equation model. Results for the effects of primary interest are shown in Figures 2 (Taiwan) and 3 (Beijing). For both Taiwan and Beijing, the structural equation models demonstrate good overall fit. The RMSEA is .057 and .066 and the CFI is .942 and .936 for Taiwan and Beijing respectively.

Coefficients for structural equation models are interpreted similarly to those for ordinary regression. We present standardized coefficients to allow comparisons with respect to magnitude of the effects. Some general patterns are worth noting before we turn to results. First, as expected, functional limitation at a given wave exhibits a strong positive effect on functional limitation in the next wave in both Taiwan and Beijing. The same is true for economic well-being. Second, as hypothesized, cross-lag effects of economic wellbeing on functional limitation, and vice versa, are negative. That is, higher functional limitation in a given wave is generally associated with lower economic well-being in the next wave, and higher economic well-being in a given wave is generally associated with lower functional limitation in the next wave. Three of the four cross-lag effects are statistically significant in each setting.

Focusing first on the results for Taiwan (Figure 2), effects of functional limitation on economic well-being are significant for both intervals, with higher levels of limitation leading to lower levels of economic well-being over time. The magnitude of the coefficient is stronger in the second interval than in the first (-.077 versus -.041). Similarly, higher economic well-being is related to lower levels of functional limitation over time, although this effect is only statistically significant in the first interval $(-.063, p<.001)$. Because we hypothesized negative associations, tests of significance are based on one-tailed tests. As in Taiwan, higher economic well-being leads to lower levels of functional limitation in 
Beijing, although the effect in this case is statistically significant only in the second interval $(-.124, \mathrm{p}<.001)$. Functional limitation leads to lower levels of economic well-being, with the magnitude being slightly more pronounced in the second compared to the first interval (-.036 versus -.023$)$. The stronger effects for the second interval in Beijing may be partly a consequence of a longer lag period, which provides a longer duration for effects to occur.

Standardized estimates of the effects of covariates on functional limitation and economic well-being are shown in Table 3. The direction and significance for the majority of variables are as would be expected and, for the most part, effects across settings are similar. For example, in both settings, increases in age are associated with decreases in economic well-being and sharp increases in functional limitation. Women have lower economic well-being than men, and more functional limitations. Being married is associated with higher economic well-being but has no influence on functional limitation. Other things being equal, ethnicity is not associated with either outcome in either setting. There is a noteworthy difference in the effect of urban residence. In both settings, residents of urban areas have higher levels of economic well-being. This is expected, given higher incomes in urban areas. But living in an urban area is associated with higher functional limitations only in Beijing. Rural areas in China are characterized by health care resources of poorer quality and quantity than those in cities, and this difference has been shown to influence health outcomes (Beach, 2001). Fewer differences in health care exist between rural and urban Taiwan.

Living arrangements and the experience of becoming widowed between survey waves are also interesting. In general, those living alone or with a spouse only have both lower economic well-being and lower functional limitation. The alternative is usually coresiding with an adult child. Coresident households likely benefit from a pooling of resources from adult children and older parents, enhancing the economic well-being of the household as a whole. As a result, coresident elderly may be more satisfied with their economic circumstances and have more assets and/or household possessions than their noncoresident counterparts; both of these factors would contribute to higher scores on our measure of economic well-being. In addition, coresidence with adult children may be a response to the onset of functional impairments, associated with the need for assistance in conducting daily tasks. Hence, those living with others are likely to have a greater number and severity of functional disorders. In contrast, becoming widowed is not related to either outcome. We had expected that becoming widowed would lead to a decline in economic well-being and to an increase in functional limitation. One possible explanation is that the time lag witnessed here is too short to detect any effects of widowhood. Another is that the family serves as a buffer against the negative effect of widowhood on economic and physical well-being. This is an area of research that requires more work.

\section{DISCUSSION}

Determining the factors that lead to better health at older ages allows for the development of policy aimed at reducing health inequalities. Yet, despite the acknowledged health advantages for persons with higher socioeconomic status, inequalities by socioeconomic status may even have increased over time. Much remains unknown 
about this robust and persistent relationship. This paper has contributed to the debate in several ways. First, we used longitudinal data to investigate potential reciprocal effects of socioeconomic status and health, rather than assume that effects operate solely in one direction. Second, we examined the relationship in Asia, which allowed us to assess the wider validity of the relationship. Third, we compared two settings that share strong cultural roots but are distinct in other important ways. In addition, we focused on older adults, a segment of the population that is growing rapidly in both settings, and a segment for which previous findings on the association between socioeconomic status and health have been less consistent.

We began by posing three questions that have not been adequately answered. The first two are whether socioeconomic status disparities in health are found in non-Western settings and whether they endure into old age. On both of these points, our results are affirmative. Higher levels of economic well-being are associated with lower levels of functional limitation among older Chinese in both Taiwan and Beijing. The third question inquired about the direction of causality between socioeconomic status and health. On this point, our results suggest that both effects operate, that is, economic well-being influences functional health over time, and functional health influences economic well-being over time.

The reciprocal effects of economic well-being and functional health found in the current study lend support to our initial hypotheses. All but one of the cross-lagged effects in each country are statistically significant, and all are in the expected direction. Taken together, the findings are consistent with those from studies based in the United States and Europe, which have found socioeconomic status differentials in functional health among older adults. Our findings further highlight the wider applicability of the associations across settings that have been examined less frequently and have very different systems of social stratification and health care. A more noteworthy contribution of this study, however, relates to the bi-directional causal effects that we observe in both settings, a finding that underscores the necessity for considering reciprocal influences in studies of socioeconomic status and health.

Some differences in effects across settings, as well as over time within settings, are worth noting. Although our explanation for these differences is speculative, it may elucidate the dynamics behind the association, particularly within the context of changes that occurred in the economies and health systems of Taiwan and Beijing during the 1990s. In both settings, the effect of functional limitation on economic well-being is significant in both periods (1993 to 1996 and 1996 to 1999 for Taiwan; 1992 to 1994 and 1994 to 1997 for Beijing) and more pronounced in the second period than in the first. The fact that our sample ages over time suggests that effects may increase in importance with age. In Beijing, the effect of economic well-being on functional limitation is stronger in the second interval, whereas in Taiwan it is stronger in the first. In China, economic growth occurred at a rapid pace during the study period, health services became much more privatized, and access to health services became more differentiated along socioeconomic lines. Hence it is plausible that economic well-being was not as important a determinant of functional health in the early 1990s, but emerged as more important during the later period along with 
widening disparities in economic well-being. This could also explain why we found a stronger effect of economic well-being on health than health on economic well-being in China during the later period. In Taiwan, a different situation unfolded. A national health insurance scheme, instituted in 1995, effectively equalized access to health services and led to a dramatic increase in health care use across all ages and social groups (Cheng and Chiang, 1997). In this regard, the diminished effect of economic well-being on functional health may be a consequence of the leveling of access to health care that occurred following implementation of access to universal health care.

The current study has several limitations. We are limited to three waves of data, and the time period of study is short. If it takes time for effects to manifest themselves, we may be underestimating reciprocal effects. In addition, the analysis is restricted to the subsample of respondents who participated in all three waves. Those who died or were nonrespondents in a given wave are excluded. To assess how these exclusions might affect our conclusions, we examined functional limitation scores and economic well-being indicators at baseline for those who died or were nonrespondents, and compared them to those who are included in the study. The results indicated that respondents who were subsequently excluded had much higher levels of functional limitation and only slightly lower or similar levels of economic well-being than those who remained in the study. Hence, if anything, these exclusions would have reduced the associations between economic well-being and functional limitation; thus again, our results may be underestimated. With these latter two limitations in mind, the findings of this study are all the more persuasive.

We suggest that future studies seek to incorporate measures that help identify the factors that give rise to associations between socioeconomic status and health. These factors will differ depending on the direction of the relationship (socioeconomic status on health versus health on socioeconomic status). To date, more attention has been paid to the factors underlying the impact of socioeconomic status on health, and less to the impact of health on socioeconomic status. As a result, the development of appropriate measures of the causes and consequences of health status within different cultural and economic groups constitutes an important topic in health and economic research. 
Table 1. Descriptive information for all measures at wave 1

\begin{tabular}{|c|c|c|c|c|}
\hline & \multicolumn{2}{|c|}{ Taiwan } & \multicolumn{2}{|c|}{ Beijing } \\
\hline & Mean & SD & Mean & SD \\
\hline \multicolumn{4}{|l|}{ MEASURES OF FUNCTIONAL } & \\
\hline ADL score & .033 & .234 & .012 & .088 \\
\hline - Dressing & .037 & .283 & 1.005 & .080 \\
\hline - Bathing & .451 & .305 & 1.038 & .232 \\
\hline - Moving around the house & .031 & .234 & 1.009 & .104 \\
\hline - Eating & .013 & .166 & 1.002 & .050 \\
\hline - Getting in/out of bed & .024 & .221 & 1.007 & .095 \\
\hline IADL score & .197 & .552 & .145 & .382 \\
\hline - Shopping & .158 & .597 & 1.111 & .410 \\
\hline - Taking train/bus & .329 & .834 & 1.224 & .527 \\
\hline - Taking care of finances & .103 & .481 & 1.101 & .397 \\
\hline Nagi score & .250 & .618 & .087 & .349 \\
\hline - climbing stairs & .296 & .705 & 1.098 & .381 \\
\hline - walking 200/300 meters & .203 & .631 & 1.077 & .341 \\
\hline \multicolumn{5}{|l|}{ MEASURES OF ECONOMIC WELL-BEING } \\
\hline \multicolumn{5}{|l|}{ Assets } \\
\hline - Land & .182 & .386 & na & na \\
\hline - Savings & .388 & .487 & na & na \\
\hline - Color TV & .971 & .167 & .630 & .430 \\
\hline - Air conditioner & .288 & .453 & na & na \\
\hline - Car & .221 & .415 & na & na \\
\hline - Electric fan & na & na & .804 & .397 \\
\hline - Refrigerator & na & na & .621 & .485 \\
\hline - Washing machine & na & na & .652 & .476 \\
\hline \multicolumn{5}{|l|}{ Subjective Well-Being } \\
\hline - Adequacy of income to cover expenses & 3.192 & .693 & 3.658 & .861 \\
\hline - Satisfaction with income & 3.622 & .927 & 3.848 & .745 \\
\hline Income (NT dollars in Taiwan/ Yuan in Beijing) & 161425.1 & 154752.7 & 150 & 151 \\
\hline
\end{tabular}

Continued on next page 
Table 1. (continued)

\begin{tabular}{|c|c|c|c|c|}
\hline & \multicolumn{2}{|c|}{ Taiwan } & \multicolumn{2}{|c|}{ Beijing } \\
\hline & Mean & SD & Mean & SD \\
\hline \multicolumn{5}{|l|}{ COVARIATES } \\
\hline Age & 70.9 & 5.2 & 67.5 & 7.8 \\
\hline Female & .454 & .498 & .517 & .450 \\
\hline Married & .670 & .470 & .740 & .439 \\
\hline Majority ethnic group & .765 & .423 & .979 & .143 \\
\hline Lives in urban area & .634 & .481 & .356 & .475 \\
\hline \multicolumn{5}{|l|}{ Education } \\
\hline - No education & .467 & .499 & .464 & .499 \\
\hline - Primary education & .337 & .471 & .295 & .456 \\
\hline - Jr. High school & .091 & .288 & .112 & .315 \\
\hline - Sr. High school & .054 & .226 & .060 & .237 \\
\hline - College & .052 & .210 & .069 & .254 \\
\hline Lives alone or with spouse only & .188 & .392 & .304 & .460 \\
\hline Widowed between waves 1 and 2 & .061 & .240 & .034 & .180 \\
\hline
\end{tabular}

na $=$ not applicable

Table 2. Fit for measurement models of functional limitation

\begin{tabular}{llll}
\hline Model & Measure of Fit & Taiwan & Beijing \\
\hline 1. Null & CFI & .000 & .000 \\
& RMSEA & .395 & .371 \\
& $X^{2}(\mathrm{df}=28)$ & 2856.33 & 1313.78 \\
2. Independent errors & CFI & .953 & .944 \\
& RMSEA & .105 & .107 \\
\multirow{5}{*}{ 3. Correlated errors } & $X^{2}(\mathrm{df}=24)$ & 576.87 & 578.31 \\
& CFI & .992 & .982 \\
& RMSEA & .050 & .071 \\
& $X^{2}(\mathrm{df}=18)$ & 111.25 & 198.35 \\
\hline
\end{tabular}


Table 3. Standardized likelihood estimates for covariates

\begin{tabular}{|c|c|c|c|c|c|c|}
\hline & \multicolumn{6}{|c|}{ Dependent Variables } \\
\hline & \multicolumn{2}{|c|}{ Wave 1} & \multicolumn{2}{|c|}{ Wave 2} & \multicolumn{2}{|c|}{ Wave 3} \\
\hline & $\begin{array}{l}\text { Economic } \\
\text { well-being }\end{array}$ & $\begin{array}{l}\text { Functional } \\
\text { Limitation }\end{array}$ & $\begin{array}{l}\text { Economic } \\
\text { well-being }\end{array}$ & $\begin{array}{l}\text { Functional } \\
\text { Limitation }\end{array}$ & $\begin{array}{l}\text { Economic } \\
\text { well-being }\end{array}$ & $\begin{array}{l}\text { Functional } \\
\text { Limitation }\end{array}$ \\
\hline \multicolumn{7}{|l|}{ TAIWAN } \\
\hline - Age & $-.054 * *$ & $.221 * * *$ & & & & \\
\hline - Female & $-.059 * *$ & $.158 * * *$ & & & & \\
\hline - Married & $.078 * * *$ & -.001 & & & & \\
\hline - Mainlander & .033 & -.005 & & & & \\
\hline - Urban & $.123 * * *$ & -.010 & & & & \\
\hline - Education & $.359 * * *$ & $-.102 * * *$ & & & & \\
\hline - Lives alone or with spouse only at wave 1 & .003 & -.028 & & & & \\
\hline - Lives alone or with spouse only at wave 2 & & & $-.088 * * *$ & $-.070 * * *$ & & \\
\hline - Lives alone or with spouse only at wave 3 & & & & & $-.080 * * *$ & $-.048 * *$ \\
\hline - Widowed between waves 1 and 2 & & & .017 & .021 & & \\
\hline - Widowed between waves 2 and 3 & & & & & .009 & .015 \\
\hline \multicolumn{7}{|l|}{ BEIJING } \\
\hline - Age & $-.095 * * *$ & $.328 * * *$ & & & & \\
\hline - Female & $-.043 * *$ & $.146 * * *$ & & & & \\
\hline - Married & $.032 *$ & -.014 & & & & \\
\hline - Han & -.007 & .018 & & & & \\
\hline - Urban & $.675 * * *$ & $-.183 * * *$ & & & & \\
\hline - Education & $.175 * * *$ & .021 & & & & \\
\hline - Lives alone or with spouse only at wave 1 & $-.136 * * *$ & $-.093 * * *$ & & & & \\
\hline - Lives alone or with spouse only at wave 2 & & & $-.032 * *$ & .017 & & \\
\hline - Lives alone or with spouse only at wave 3 & & & & & $-.035 * *$ & $-.092 * * *$ \\
\hline - Widowed between waves 1 and 2 & & & .002 & .033 & & \\
\hline - Widowed between waves 2 and 3 & & & & & .010 & .014 \\
\hline
\end{tabular}

$* \mathrm{p}<.05 * * \mathrm{p}<.01 \quad * * * \mathrm{P}<.001$; two-tailed test 
Figure 1. Model of cross-lagged reciprocal effects of latent functional limitation variables and socioeconomic status scores in Taiwan and Beijing

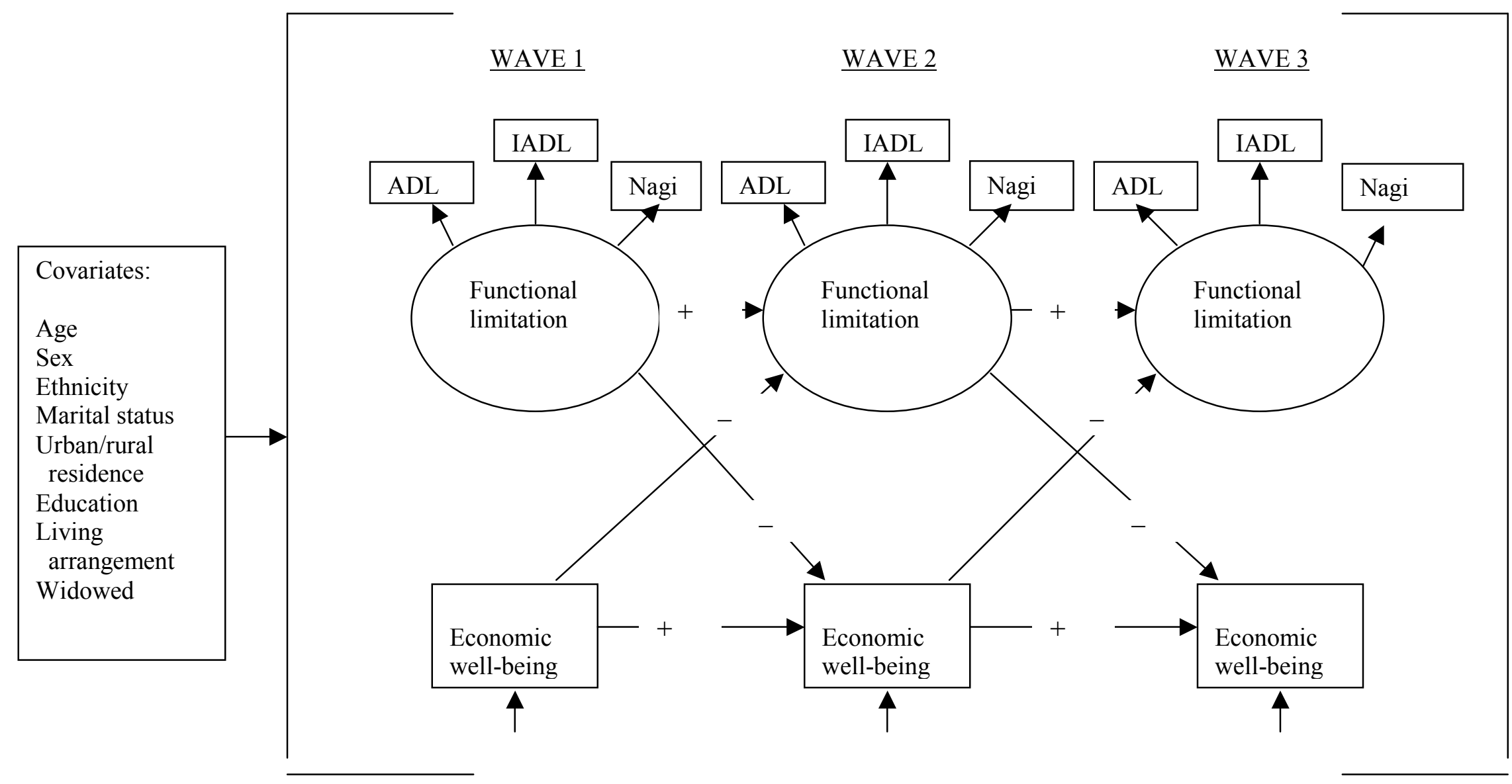

$+=$ positive effect; $-=$ negative effect

$\mathrm{ADL}=$ activities of daily living; IADL = instrumental activities of daily living; Nagi = Nagi physical functioning tasks. 
Figure 2. Standardized likelihood estimates of functional limitation, economic well-being, and cross-lag effects, Taiwan

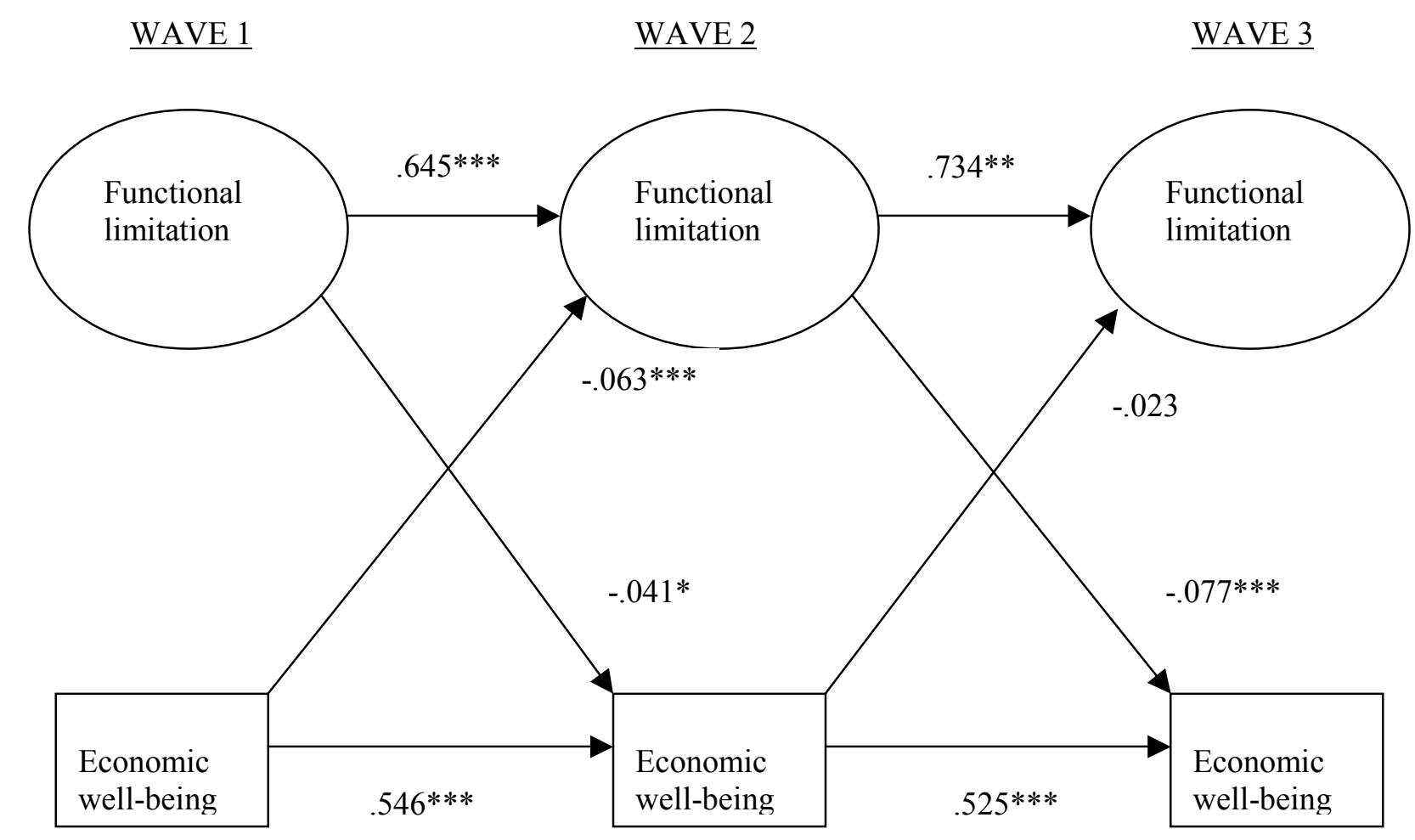

$* \mathrm{p}<.05 * * \mathrm{p}<.01 * * * \mathrm{p}<.001 ;$ one-tailed test $X^{2}(\mathrm{df}=143)=1293.02 ; \mathrm{CFI}=.942 ; \mathrm{RMSEA}=.057$ 
Figure 3. Standardized likelihood estimates of functional limitation, economic well-being, and cross-lag effects, Beijing

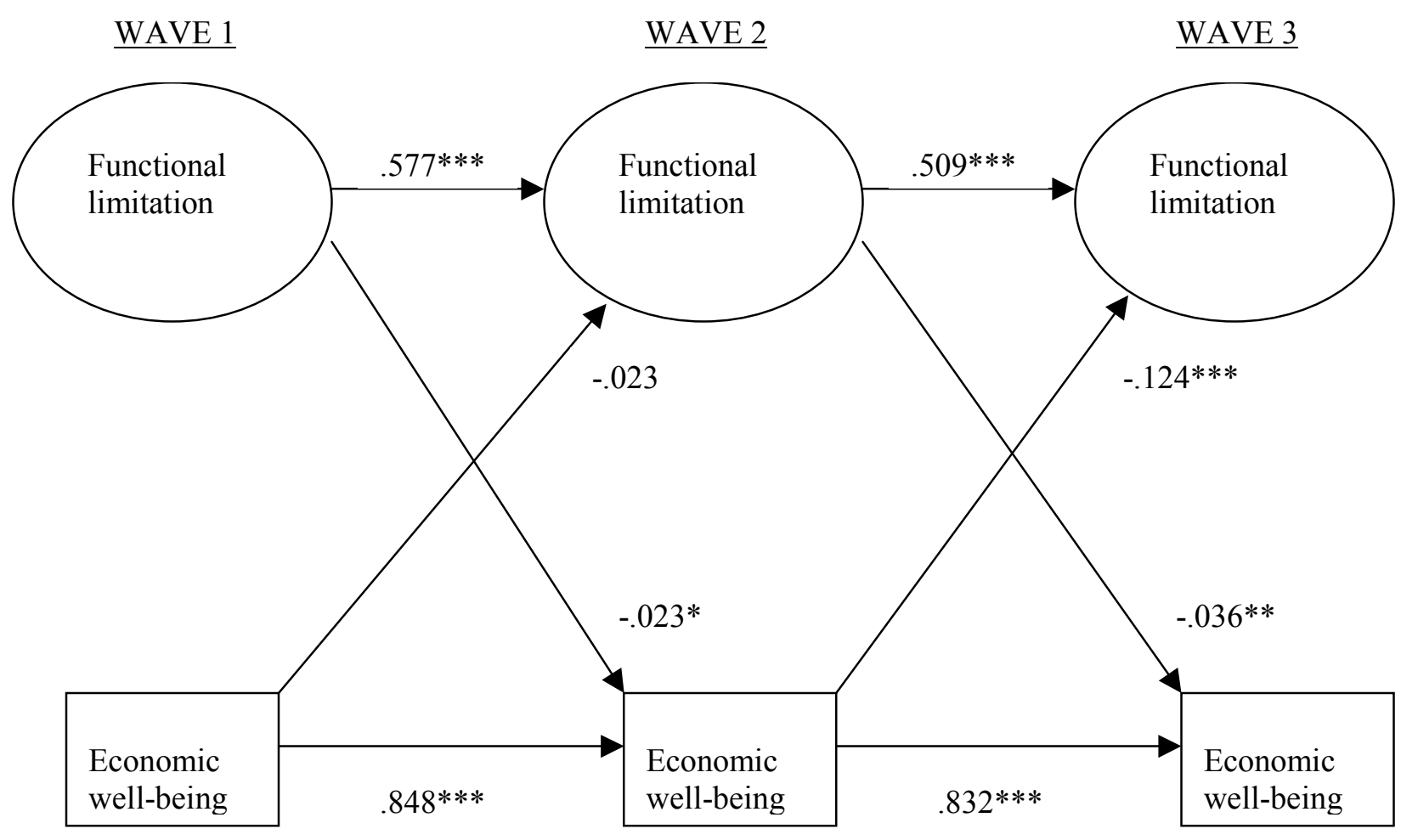

$* \mathrm{p}<.05 * * \mathrm{p}<.01 * * * \mathrm{p}<.001 ;$ one-tailed test $X^{2}(\mathrm{df}=143)=1230.80 ; \mathrm{CFI}=.936 ; \mathrm{RMSEA}=.066$ 


\section{References}

Anderson, J.C. and Gerbing, D.W. 1988. Structural equation modeling in practice: A review and recommended two-step approach. Psychological Bulletin, 103, 411-423.

Antonovsky, A. 1967. Social class, life expectancy and overall mortality. Milbank Memorial Fund Quarterly, 45, 31-73.

Arbuckle, J. L. and Wothke, W. 1999. AMOS 4.0 User's Guide. Chicago: SPSS Inc.

Backlund, E., Sorlie, P.D., and Johnson, N.J. 1996. The shape of the relationship between income and mortality in the United States: Evidence from the National Longitudinal Mortality Study. Annals of Epidemiology, 6, 1-9.

Beach, M. 2001. China's rural health care gradually worsens. Lancet, 358, 567.

Beckett, M. 2000. Converging health inequalities in later life: An artifact of mortality selection? Health and Social Behavior, 41, 106-119.

Bentler, P.M. 1990. Comparative fit indexes in structural models. Psychological Bulletin, $107,238-246$.

Bollen, K.A. 1989. Structural Equations with Latent Variables. New York: Wiley.

Carr-Hill, R. 1987. The inequalities in health debate: A critical review of the issues. Journal of Social Policy, 16, 509-542.

Cheng S.H. and Chiang, T.L. 1997. The effect of universal health insurance on health care utilization in Taiwan: Results from a natural experiment. Journal of the American Medical Association, 278, 2, 89-93.

Conover, P.W. 1973. Social class and chronic illness. International Journal of Health Sciences, 3, 357-368.

Department of Social Medicine. 1995. Report of the Beijing Multidimentional Longitudinal Study on Aging. Beijing: Beijing Geriatric Clinical and Research Center.

Dunteman, G. 1989. Principal Components Analysis. Quantitative Applications in the Social Sciences No. 69. Newbury Park, CA: Sage Publications.

Ebrey, P.B. 2000. China. New York: Cambridge University Press.

Elo, I.T. and Preston, S.H. 1995. Educational differentials in mortality: United States, 197985. Social Science and Medicine, 42, 47-57. 
Fang, Y. 1990. Support for the elderly: The Chinese way. In Zeng,Y., Zhang, C., and Peng, S. Changing Family Structure and Population Aging in China: A Comparative Approach (Pp. 341-358). Beijing: Peking University Press.

Feldman, J.J., Makuc, D.M., Kleinman, J.C., and Cornoni-Huntley, J. 1989. National trends in educational differentials in mortality. American Journal of Epidemiology, 129, 919-933.

Filmer, D. and Pritchett, L.H. 1999. The effect of household wealth on educational attainment: Evidence from 35 countries. Population and Development Review, 25, $1,85-120$.

Gregorio, D.I., Walsh, S.J., and Paturzo, D. 1997. The effects of occupation-based social position on mortality in a large American cohort. American Journal of Public Health, 87, 1472-1475.

Grundy, E. and Glaser, K. 2000. Socio-demographic differences in the onset and progression of disability in early old age: A longitudinal study. Age and Ageing, 19, 149-157.

Gu, D. and Z. Yi. 2004. Sociodemographic effects on the onset and recovery of ADL disability among Chinese oldest-old. Demographic Research. 11, Article 1, 1-41.

Guralnik, J.M., Land, K.C., Blazer, D., Fillenbaum, G.G., and Branch, L.G. 1993. Educational status and active life expectancy among older blacks and whites. New England Journal of Medicine, 329, 110-116.

Hemingway, H., Nicholson, A., and Marmot, M. 1997. The impact of socioeconomic status on health functioning as assessed by the SF-36 Questionnaire: The Whitehall II Study. American Journal of Public Health, 87, 1484-1490.

Hermalin, A.I. and Myers, L.G. 2002. Aging in Asia: Facing the crossroads. In A. I. Hermalin (Ed.). The Well-Being of the Elderly in Asia: A Four-Country Comparative Study (Pp. 1-24). Ann Arbor, MI: University of Michigan Press.

Hermalin, A.I., Liang, J., and Chang, M.C. 1989. Survey of Health and Living Status of the Elderly in Taiwan: Questionnaire and survey design. Elderly in Asia Report, 89-1, December.

Hermalin, A.I., Ofstedal, M.B., and Chang, M.C. 1996. Types of supports for the aged and their providers in Taiwan. In Hareven, T. (Ed.) Aging and Generational Relations Over the Life Course: A Historical and Cross-Cultural Perspective (Pp. 400-437). New York: Walter de Gruyter.

House, J.S., Kessler, R.C., Herzog, A.R., Kinney, A.M., Mero, R.P., and Breslow, M.F. 1990. Age, socioeconomic status and health. The Milbank Quarterly, 68, 383-411. 
Hurd, M.D., McFadden, D. and Merrill, A. 1999. Predictors of mortality among the elderly. In NBER Working Paper No. 7440. Cambridge, MA: National Bureau of Economic Research.

Jiang, J., Tang, Z., Meng, X.J., and Futatsuka, M. 2002. Demographic determinants for change in activities of daily living: A cohort study of the elderly people in Beijing. Journal of Epidemiology, 12, 280-286.

Jiang, Z. and Zhang, L. 2000. Fertility decline and population policy in China. In Korean Institute of Health and Social Affairs and the United Nations Population Fund (Eds.), Low Fertility and Policy Responses to Issues of Ageing and Welfare (Pp. 195-225). Seoul: Korean Institute of Health and Social Affairs, United Nations Population Fund.

Kaplan, G.A., Strawbridge, W.J., Camacho, T., and Cohen, R.D. 1993. Factors associated with change in physical functioning in the elderly: A six-year prospective study. Journal of Aging and Health, 5, 140-153.

Katz, S., A.B. Ford, R.W. Moskowitz, B.A. Jackson, and M.W. Jaffee. 1963. Studies of illness in the aged: The index of ADL, a standardized measure of biological and psychosocial function. Journal of the American Medical Association, 185, 914-919.

Kawachi, I., Kennedy, B.P., Lochner, K., and Prothrow-Stith, D. 1997. Social capital, income inequality and mortality. American Journal of Public Health, 87, 14911498.

Kessler, R.C. and Greenberg, D.F. 1981. Linear Panel Analysis: Models of Quantitative Change. New York: Academic Press.

Kirchgassler, K.U. 1998. Health and social inequities in the Federal Republic of Germany. Social Science and Medicine, 31, 249-256.

Kitagawa, E.M. and Hauser, P.M. 1973. Differential Mortality in the United States: A Study of Socioeconomic Epidemiology. Cambridge, MA: Harvard University Press.

Kline, R.B. 1998. Principles and Practice of Structural Equation Modeling. New York: Guilford Press.

Knesebeck, O. von dem, Luschen, G., Cockerham, W.C., and Siegrist, J. 2003. Socioeconomic status and health among the aged in the United States and Germany: A comparative cross-sectional study. Social Science and Medicine, 57, 1643-1652.

Lagasse, R., Humblet, C.P., Lenaerts, A., Godin, I., and Moens, G.F.G. 1990. Health and social inequalities in Belgium. Social Science and Medicine, 31, 237-248. 
Lantz, P. M., House, J.S., Lepkowski, J.M., Williams, D.R., Mero, R.P., and Chen, J. 1998. Socioeconomic factors, health behaviors and mortality. Journal of the American Medical Association, 279, 1703-1708.

Lawton, M.P. and Brody, E. 1969. Assessment of older people: Self-maintaining and instrumental activities of daily living. The Gerontologist, 9, 179-186.

Lee, Y.J., Parish, W.L., and Willis, R.J. 1994. Sons, daughters and intergenerational support in Taiwan. American Journal of Sociology, 99, 1010-1041.

Liang, J., Liu, X., and Gu, S. 2001. Transitions in functional status among older people in Wuhan, China: Socioeconomic differentials. Journal of Clinical Epidemiology, 54, 1126-1138.

Link, B.G. and Phelan, J. 1995. Social conditions as fundamental causes of disease. Journal of Health and Social Behavior, 36, 80-94.

Mackenbach, J.P., Kunst, A.E., Cavelaars, A.E.J.M., Groenhof, F., Geurts, J.J.M., and EU Working Group on Socioeconomic Inequalities in Health. 1997. Socioeconomic inequalities in morbidity and mortality in western Europe. The Lancet, 349, 16551659.

Markides, K.S. and Machalek, R. 1984. Selective survival, aging, and society. Archives of Gerontology and Geriatrics, 3, 207-222.

Marmot, M.G., Shipley, M., and Rose, G. 1984. Inequalities in death: Specific explanations of a general pattern? Lancet, 1, 1003-1006.

Melzer, D., Izmirlian, G., Leveille, S.G., and Guralnik, J.M. 2001. Educational differences in the prevalence of mobility disability in old age: The dynamics of incidence, mortality, and recovery. Journal of Gerontology: Social Sciences, 56B, S294-S301.

Nagi, S.Z. 1965. Some conceptual issues in disability and rehabilitation. In Sussman, M. B. (Ed.), Sociology and Rehabilitation (Pp. 100-113). Washington, D.C.: American Sociological Association.

National Research Council. 2001. Preparing for an Aging World: The Case for CrossNational Research. Washington, DC: National Academy Press.

Pamuk, E.R. 1985. Social class inequality in mortality from 1921 to 1972 in England and Wales. Population Studies, 39, 17-31.

Pappas, G., Queen, S., Hadden, W., and Fisher, G. 1993. The increasing disparity in mortality between socioeconomic groups in the United States, 1960 and 1986. New England Journal of Medicine, 329, 103-109. 
Poston, D.L. 1992. Fertility trends in China. In Poston, D.L. and Yaukey D. (Eds.), The Population of Modern China (Pp. 277-286). New York: Plenum Press.

Queen, S., Pappas, G., Hadden, W., and Fisher, G. 1994. The widening gap between socioeconomic status and mortality. Statistical Bulletin of the Metropolitan Insurance Company, 75, 31-35.

Robert, S. and House, J.S. 1994. Socioeconomic status and health across the life course. In Abeles, R.P., Gift, H.C., and Ory, M.G. (Eds.), Aging and Quality of Life. New York: Springer.

Ross, C. and Wu, C. 1996. Education, age and the cumulative advantage in health. Journal of Health and Social Behavior, 37, 104-120.

Ross, C. and Wu, C. 1995. The links between education and health. American Sociological Review, 60, 719-745.

Roy, D. 2003. Taiwan: A Political History. Ithaca, NY: Cornell University Press.

Rubin, D.B., and Schenker, N. 1986. Multiple imputation for interval estimation from simple random samples with ignorable nonresponse. Journal of the American Statistical Association, 81, 366-374.

Shi, L. 1993. Health care in China: A rural-urban comparison after the socioeconomic reforms. Bulletin of the World Health Organization, 71, 723-736.

Smith, J.P. 1999. Healthy bodies and thick wallets: The dual relation between health and economic status. Journal of Economic Perspectives, 13, 145-166.

Spruit, I.P. 1990. Health and social inequities in the Netherlands. Social Science and Medicine, 31, 319-329.

Sundquist, J. and Johansson, S.E. 1997. Indicators of socio-economic position and their relation to mortality in Sweden. Social Science and Medicine, 45, 1757-1766.

Tang, Z., Wang, H.X., Meng, C., Wu, X.G., Ericsson, K., Winblad, B., and Pei, J.J. 1999. The prevalence of functional disability in activities of daily living among elderly Beijing Chinese. Archives of Gerontology and Geriatrics, 29, 115-125.

Townsend, P. and Davidson, N. 1982. Social Inequalities in Health: The Black Report. London: Penguin Books.

United Nations. 2001. World Population Prospects: The 2000 Revision. New York: United Nations. 
Victor, C.R. 1991. Continuity or change: Inequalities in health in later life. Ageing and Society, 11, 23-39.

Whyte, M.K. 2003. China's revolutions and intergenerational relations. In Whyte, M.K. (Ed.), China's Revolutions and Intergenerational Relations (Pp. 3-32). Ann Arbor: University of Michigan Press.

Wilkinson, R.G. 1986. Socio-economic differences in mortality: Interpreting the data on their size and trends. In Wilkinson, R.G. (Ed.), Class and Health: Research and Logitudinal Data. London: Tavistock.

Williams, D.R. 1990. Socioeconomic differentials in health: A review and redirection. Social Psychology Quarterly, 53, 81-99.

Winkleby, M.A., Jatulis, D.E., Frank, E., and Fortmann, S.P. 1992. Socioeconomic status and health: How education, income and occupation contribute to risk factors for cardiovascular disease. American Journal of Public Health, 82, 816-820.

Wolfson, M., Rowe, G., Gentleman, J.E., and Tomiak, M. 1993. Career earnings and death: A longitudinal analysis of older Canadian men. Journal of Gerontology, 48, S167S179.

Yu, L.C. and Wang, M. 1993. Social status, physical, mental health, well-being and self evaluation of elderly in China. Journal of Cross-Cultural Gerontology, 8, 147-159.

Zimmer, Z., Chayovan, N., Lin, H.S., and Natividad, J.N. 2004. How indicators of socioeconomic status relate to physical functioning of older adults in three Asian societies. Research on Aging, 26, 224-258.

Zimmer, Z. and Kwong, J. 2004. Socioeconomic status and health among older adults in rural and urban China. Journal of Aging and Health, 16, 44-70.

Zimmer, Z., Liu, X., Hermalin, A.I., and Chuang, Y.L. 1998. Educational attainment and transitions in functional status among older Taiwanese. Demography, 35, 361-375. 


\section{POLICY RESEARCH DIVISION WORKING PAPERS}

If still in print, single copies of up to three working papers from 1989 through 2003 are available free of charge.

Beginning with the 2004 issues, working papers are no longer available in print format. Instead they are distributed electronically. As each new paper is completed subscribers are notified by e-mail and a link to the paper is provided.

To subscribe to the Policy Research Division working paper e-mail notification list, or to obtain back issues from 1989 to 2003, please send your request to prdwp@popcouncil.org.

PDFs of recent issues are available at www.popcouncil.org/publications/wp/prd/rdwplist.html

2005

197 Kristine R. Baker, Mary Beth Ofstedal, Zachary Zimmer, Zhe Tang, and Yi-Li Chuang, "Reciprocal effects of health and economic well-being among older adults in Taiwan and Beijing."

196 Mark R. Montgomery and Paul C. Hewett, "Poverty and children's schooling in urban and rural Senegal."

2004

195 Luciana Suran, Sajeda Amin, Lopita Huq, and Kobita Chowdury, "Does dowry improve life for brides? A test of the bequest theory of dowry in rural Bangadesh.”

194 Barbara S. Mensch, Monica J. Grant, Mary P. Sebastian, Paul C. Hewett, and Dale Huntington. "The effect of a livelihoods intervention in an urban slum in India: Do vocational counseling and training alter the attitudes and behavior of adolescent girls?"
193 Amanda Ritchie, Cynthia B. Lloyd, and Monica Grant. "Gender differences in time use among adolescents in developing countries: Implications of rising school enrollment rates."

192 John Bongaarts. "Long-range trends in adult mortality: Models and projection methods."

191 John Koku Awoonor-Williams, Ellie S. Feinglass, Rachel Tobey, Maya N. Vaughan-Smith, Frank K. Nyonator, Tanya C. Jones, and James F. Phillips, "Bridging the gap between evidence-based innovation and national healthsector reform in Ghana."

190 Kelly Hallman, "Socioeconomic disadvantage and unsafe sexual behaviors among young women and men in South Africa."

189 Toshiko Kaneda, Zachary Zimmer, and Zhe Tang, "Differentials in life expectancy and active life expectancy by socioeconomic status among older adults in Beijing."

\footnotetext{
* No longer available as a printed publication. Download electronic file from Web site only.
} 
188 Cynthia B. Lloyd and Monica J. Grant, "Growing up in Pakistan: The separate experiences of males and females."

187 Zachary Zimmer, Xianghua Fang, Toshiko Kaneda, Zhe Tang, and Julia Kwong. "Trends and transitions in children's coresidence with older adults in Beijing municipality."

186 Sajeda Amin and Alaka M. Basu. "Popular perceptions of emerging influences on mortality and longevity in Bangladesh and West Bengal."

185 John Bongaarts. "Population aging and the rising cost of public pensions."

184 Mark R. Montgomery and Paul C. Hewett. "Urban poverty and health in developing countries: Household and neighborhood effects.

\section{3}

183 Agnes R. Quisumbing and Kelly Hallman. "Marriage in transition: Evidence on age, education, and assets from six developing countries."

182 Paul C. Hewett, Barbara S. Mensch, and Annabel S. Erulkar, "Consistency in the reporting of sexual behavior among adolescent girls in Kenya: A comparison of interviewing methods."
Zachary Zimmer, Linda G. Martin, and Hui-Sheng Lin, "Determinants of old-age mortality in Taiwan."

180 Frank K. Nyonator, J. Koku Awoonor-Williams, James F. Phillips, Tanya C. Jones, and Robert A. Miller, "The Ghana Community-based Health Planning and Services Initiative: Fostering evidence-based organizational change and development in a resourceconstrained setting."

179 John Bongaarts and Griffith Feeney, "Estimating mean lifetime."

178 Elizabeth F. Jackson, Patricia Akweongo, Evelyn Sakeah, Abraham Hodgson, Rofina Asuru, and James F. Phillips, "Women's denial of having experienced female genital cutting in northern Ghana: Explanatory factors and consequences for analysis of survey data."

177 John Bongaarts, "Completing the fertility transition in the developing world: The role of educational differences and fertility preferences."

176 Cynthia B. Lloyd and Paul C. Hewett, "Primary schooling in sub-Saharan Africa: Recent trends and current challenges."

175 James F. Phillips, Tanya C. Jones, Frank K. Nyonator, and Shruti Ravikumar, "Evidence-based development of health and family planning programs in Bangladesh and Ghana."

\footnotetext{
* No longer available as a printed publication. Download electronic file from Web site only.
} 
174 Geoffrey McNicoll, "Population and development: An introductory view."

173 Paul Demeny, "Population policy: A concise summary."

172 Zachary Zimmer, Napaporn Chayovan, Hui-Sheng Lin, and Josefina Natividad, "How indicators of socioeconomic status relate to physical functioning of older adults in three Asian societies."

171 Sajeda Amin and Nagah H. AlBassusi, "Wage work and marriage: Perspectives of Egyptian working women."

170 Ravai Marindo, Steve Pearson, and John B. Casterline, "Condom use and abstinence among unmarried young people in Zimbabwe: Which strategy, whose agenda?"

169 Zachary Zimmer and Julia Dayton, "The living arrangements of older adults in sub-Saharan Africa in a time of HIV/AIDS."

168 Paul C. Hewett, Annabel S. Erulkar, and Barbara S. Mensch, "The feasibility of computerassisted survey interviewing in Africa: Experience from two rural districts in Kenya."

* No longer available as a printed publication. Download electronic file from Web site only. 